02

\title{
Новые линии в спектрах ИК люминесценции высокого разрешения монокристаллов SiC политипов 4H и $6 \mathrm{H}$
}

\author{
(C) К.Н. Болдырев ${ }^{1,2}$, Д.Д. Гуценко ${ }^{1,2}$, С.А. Климин ${ }^{1}$, Н.Н. Новикова ${ }^{1}$, Б.Н. Маврин ${ }^{1}$ \\ М.Н. Маякова ${ }^{3}$, В.М. Хныков ${ }^{4}$ \\ ${ }^{1}$ Институт спектроскопии РАН, \\ 108840 Троицк, Москва, Россия \\ ${ }^{2}$ Московский фризико-технический институт (национальный исследовательский университет), \\ 141701 Долгопрудный, Московская обл., Россия \\ ${ }^{3}$ Институт общей фоиики им. А.М. Прохорова РАН, \\ 119991 Москва, Россия \\ ${ }^{4} \mathrm{OOO} \mathrm{„Гранник“,}$ \\ 127051 Москва, Россия \\ e-mail: kn.boldyrev@gmail.com
}

Поступила в редакцию 15.03.2020 г.

В окончательной редакции 15.05.2020 г.

Принята к публикации 20.05.2020 г.

Проведено исследование низкотемпературных спектров ИК люминесценции и поглощения высокого разрешения нелегированных высококачественных монокристаллов $\mathrm{SiC}$ гексагональных модификаций 4Н и $6 \mathrm{H}$. Обнаружены узкие линии, имеющие ширины менее $0.2 \mathrm{~cm}^{-1}$, часть из которых наблюдалась впервые. Найдено, что часть линий в модификации $4 \mathrm{H}$ и $6 \mathrm{H}$ имеют схожую структуру, однако линии в SiC-4H смещены в высокоэнергетичную часть спектра на $\sim 180 \mathrm{~cm}^{-1}$. Для наиболее интенсивного квартета в области $1.3 \mu \mathrm{m}$ по спектрам люминесценции и поглощения удалось построить энергетическую структуру уровней как для модификации $4 \mathrm{H}$, так и для $6 \mathrm{H}$.

Ключевые слова: карбид кремния, $\mathrm{SiC}$, люминесценция, высокое разрешение, центры окраски.

DOI: $10.21883 /$ OS.2020.09.49863.97-20

\section{Введение}

Карбид кремния ( $\mathrm{SiC})$ представляет собой неорганическое химическое соединение кремния с углеродом. Он существует в виде ряда кристаллических форм политипов [1], характеризующихся разным способом упаковки атомов в элементарной ячейке. Структура кристаллической решетки карбида кремния такова, что для одного и того же химического соединения возможны структурные формы, совпадающие по двум измерениям и отличающиеся в третьем. Таким образом, различные политипы представляют собой атомные слои, расположенные в определенной последовательности. Политипы карбида кремния характеризуются числом атомных слоев в элементарной ячейке и типом решетки Бравэ $2 \mathrm{H}, 3 \mathrm{C}, 4 \mathrm{H}, 6 \mathrm{H}, 15 \mathrm{R}$ и т.д. Благодаря полиморфизму карбида кремния в нем существует большое разнообразие центров окраски, характерных для различных политипов, схожих по свойствам с хорошо изученным $\mathrm{NV}$-дефектом в алмазе [2], образующимся из-за связи вакансии углерода с атомом азота.

Широкие возможности для применения центров окраски в алмазе (в спектроскопии одиночных квантовых объектов, квантовых вычислениях, квантовой магнитометрии и др.) [3-5] стимулировали исследования по поиску центров окраски в других веществах, в частности в карбиде кремния [6]. Впервые вакансионные центры в карбиде кремния были обнаружены методом ЭПР [7]. В работах $[8,9]$ в результате экспериментов по оптически детектируемому магнитному резонансу (ОДМР) было показано, что основное состояние вакансионного центра (V-центра, представляющего собой связанные вакансии кремния и углерода) в карбиде кремния обладает спином $S=3 / 2$. Также найдены нейтральные вакансии с основным состоянием $S=1$. В работах [10-12] было показано, что на центрах окраски карбида кремния можно создавать оптическое выстраивание спиновых подуровней при комнатных температурах. В работах [1316] продемонстрирована возможность использования дефектных люминесцирующих центров $\mathrm{SiC}$ в квантовой сенсорике (в частности, в создании высокочувствительных датчиков температуры и магнитного поля) благодаря оптическому отклику этих центров окраски на слабые изменения ряда внешних параметров.

Использование центров окраски $\mathrm{SiC}$ в качестве источников одиночных фотонов $[17,18]$ имеет дальнейшие применения в квантовой радиометрии, квантовых изображениях со сверхразрешением и др. В работе [19] проведен подробный обзор результатов, полученных в этой области. Согласно данным [19], известно, что в спектрах люминесценции номинально чистого карбида кремния различных политипов наблюдаются много- 
численные относительно узкие линии в спектральной области 670-1131 $\mathrm{cm}^{-1}$. Насколько нам известно, не было сообщений о наблюдении люминесценции в чистом карбиде кремния в важной для телекоммуникаций спектральной области вблизи $1.5 \mu \mathrm{m}$.

По сравнению с NV-центрами в алмазе люминесцирующие центры окраски в карбиде кремния имеют ряд преимуществ, в частности обладают большим временем когерентности [20] даже при комнатных температуpax, что открывает новые возможности для квантовых применений. Кроме того, фотолюминесценция центров окраски в карбиде кремния наблюдается в ближнем и среднем ИК диапазонах спектра, что делает их также перспективными в биомедицинских исследованиях и системах волоконной оптики. Принимая во внимание также бо́льшую технологичность изготовления и обработки карбида кремния по сравнению с алмазом, можно заключить, что различные люминесцирующие центры окраски карбида кремния являются подходящими в качестве альтернативы NV-центров в алмазе [17].

Настоящая работа ставит своей целью исследование центров окраски монокристаллов $\mathrm{SiC}$ политипов 4Н и 6Н методами спектроскопии комбинационного рассеяния света (КРС), спектроскопии поглощения и люминесценции с высоким спектральным разрешением. Это позволит уточнить результаты предыдущих исследований по данной теме, а также найти новые центры окраски в нелегированных монокристаллах карбида кремния, потенциально пригодных для практических применений.

\section{1. Методика эксперимента}

Образцы для исследования были получены методом физического осаждения из паровой фазы (PVD) в интервале температур $1750-2750 \mathrm{~K}$ в разреженной нейтральной атмосфере. В качестве исходного сырья использовался высокочистый поликристаллический карбид кремния. Образцы размерами до $10 \times 10 \times 10 \mathrm{~mm}$ представляли собой однородные слегка окрашенные в желтый цвет кристаллы. Для подтверждения кристаллической структуры (политипа) применялись методы КРС и ИК отражения.

Спектры отражения при комнатной температуре были получены на фурье-спектрометре Bruker IFS 66V с использованием отражательной приставки с углом отражения $15^{\circ}$ (близко к нормали) в среднем ИК диапазоне, в качестве детектора излучения служил пироприемник DLaTGS. Спектры KРC при комнатной температуре были получены на многоканальном спектрометре с тройным монохроматором в режиме вычитания дисперсии в геометрии „обратное рассеяние“. Для возбуждения КРС использовался аргоновый лазер с длиной волны $514.5 \mathrm{~nm}$, регистрация осуществлялась с помощью охлаждаемой жидким азотом CCD-камеры фирмы Prinston Instruments, спектральное разрешение составляло $2 \mathrm{~cm}^{-1}$.
Измерение спектров поглощения и люминесценции проводилось с помощью фурье-спектрометра высокого разрешения Bruker IFS 125HR, снабженного оптическим гелиевым криостатом замкнутого цикла CryoMech ST403 и самодельным люминесцентным модулем-приставкой. Для возбуждения люминесценции использовался диодный лазер с длиной волны $405 \mathrm{~nm}$ и мощностью излучения $50 \mathrm{~mW}$ (пятно фокуса диаметром $0.5 \mathrm{~mm}$ ). Регистрация спектров люминесценции проводилась при помощи высокочувствительного приемника InGaAs.

\section{2. Результаты и обсуждение}

Для характеризации образцов (определения политипа исследуемых кристаллов $\mathrm{SiC}$ ) применялись методы ИК отражения и КРС. Эти методы дают взаимодополняющую информацию о фононном спектре. Кроме этого, если в спектрах отражения работает приповерхностный слой на глубине порядка длины волны, в спектрах КРС в случае прозрачных кристаллов, каким является исследуемый карбид кремния, можно получить информацию о более глубоких слоях в объеме, что важно для анализа однородности полученных образцов. Примитивная ячейка кристаллической структуры кристалла $\mathrm{SiC}-6 \mathrm{H}$ содержит большее число атомов, чем ячейка $\mathrm{SiC}-4 \mathrm{H}$ (12 атомов против 8 соответственно) [21]. В соответствии с этим и число оптических колебательных мод для кристалла $\mathrm{SiC}-4 \mathrm{H}$ больше (30 против 21). На рис. 1 представлены спектры отражения от двух монокристаллов. Один образец показал более богатую структуру (синий спектр) в сравнении с другим (красный спектр), что обусловлено появлением новых фононов в случае политипа $\mathrm{SiC}-6 \mathrm{H}$.

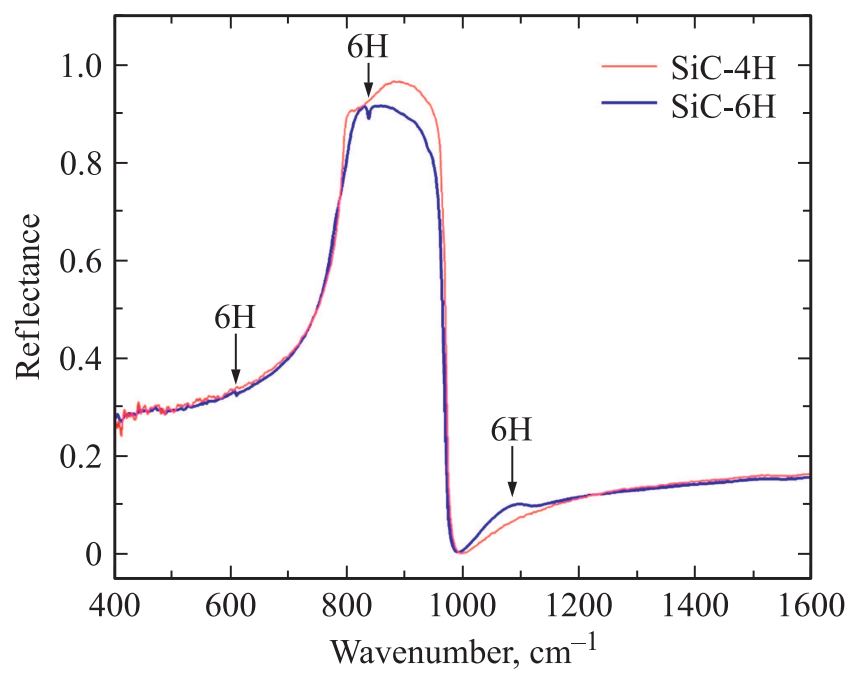

Pис. 1. Спектры отражения монокристаллов $\mathrm{SiC}$ (политип $4 \mathrm{H}$ - красная линия, $6 \mathrm{H}-$ синяя линия) в среднем ИК диапазоне при комнатной температуре. 


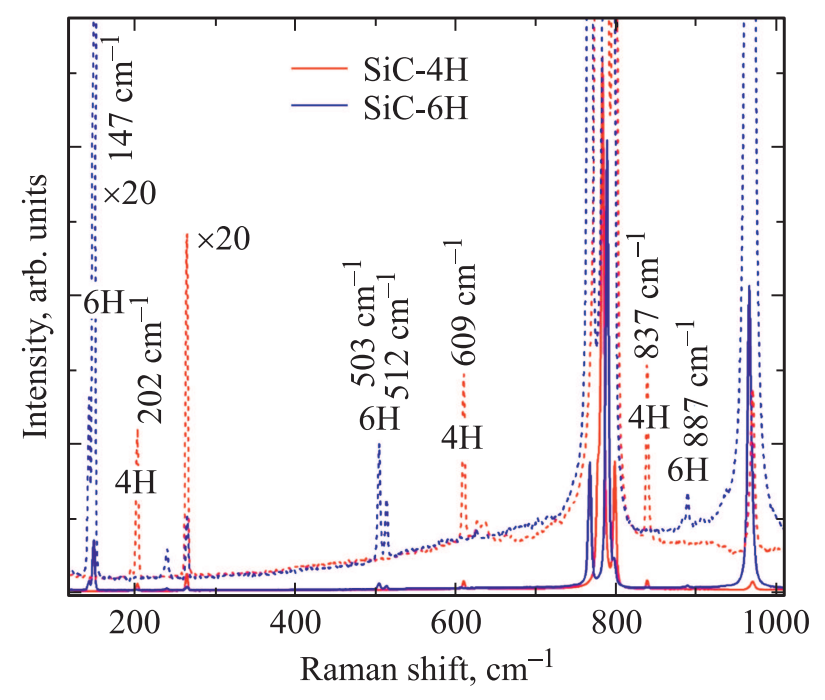

Pис. 2. Спектры КРС монокристаллов $\mathrm{SiC}$ (политип $4 \mathrm{H}-$ красная линия, $6 \mathrm{H}-$ синяя линия) при комнатной температуре. Пунктирными линиями показаны спектры в масштабе $\times 20$.

На рис. 2 представлены спектры КРС для двух исследуемых образцов, по которым удалось однозначно идентифицировать политипные структуры $\mathrm{SiC}-4 \mathrm{H}$ и $\mathrm{SiC}-$ 6Н. Так же как и в случае спектров ИК отражения, для образца $\mathrm{SiC}-6 \mathrm{H}$ наблюдается большее число колебательных мод. Наиболее характерной для идентификации политипов $\mathrm{SiC}$ является низкочастотная область спектра, в которой наблюдаются линии, проявляющиеся из-за складывания зоны Бриллюэна. Акустические фононы модификации $2 \mathrm{H}$ из середины зоны становятся оптически активными для политипов с удвоением $(4 \mathrm{H})$ и утроением (6Н). При этом в спектре КРС кристалла $\mathrm{SiC}-6 \mathrm{H}$ появляются моды вблизи $147 \mathrm{~cm}^{-1}$, а в случае кристалла $\mathrm{SiC}-4 \mathrm{H}$ - моды вблизи $202 \mathrm{~cm}^{-1}$ [22,23]. Исследование в разных точках образца не показало изменений в спектрах, что говорит об однородности полученных образцов.

На рис. 3 представлены обзорные спектры ИК люминесценции при температуре 5 К. По спектрам видно множество очень узких линий, некоторые сгруппированы в дублеты, триплеты и квартеты. В таблице приведены более подробные результаты измерений для сходных по характеру наборов линий для политипов $4 \mathrm{H}$ и $6 \mathrm{H}$, смещенных друг относительно друга (в таблице сходные линии отделены друг от друга двойными линиями). Некоторые из наблюдаемых линий по положению были близки к представленным в работах $[19,24,25]$, однако нами также обнаружено множество новых линий, отсутствующих в литературе. Примечательной особенностью спектра являются четыре высокоинтенсивные узкие линии (для каждого из исследуемых политипов, рис. 4), расстояния между которыми практически одинаковы для образцов $\mathrm{SiC}-4 \mathrm{H}$ и $\mathrm{SiC}-6 \mathrm{H}$. Эти линии проявляются также в спектрах поглощения, и анализ их температурных зависимостей в соответствии с распределением
Больцмана позволил построить схему энергетических уровней, ответственных за возникновение этого высокоинтенсивного квартета для обоих политипных модификаций. Схема представлена на вставке рис. 4.

Еще одна особенность обнаруженных спектральных линий заключается в том, что несколько дублетов и одиночных линий политипа $4 \mathrm{H}$ находятся на прибли-

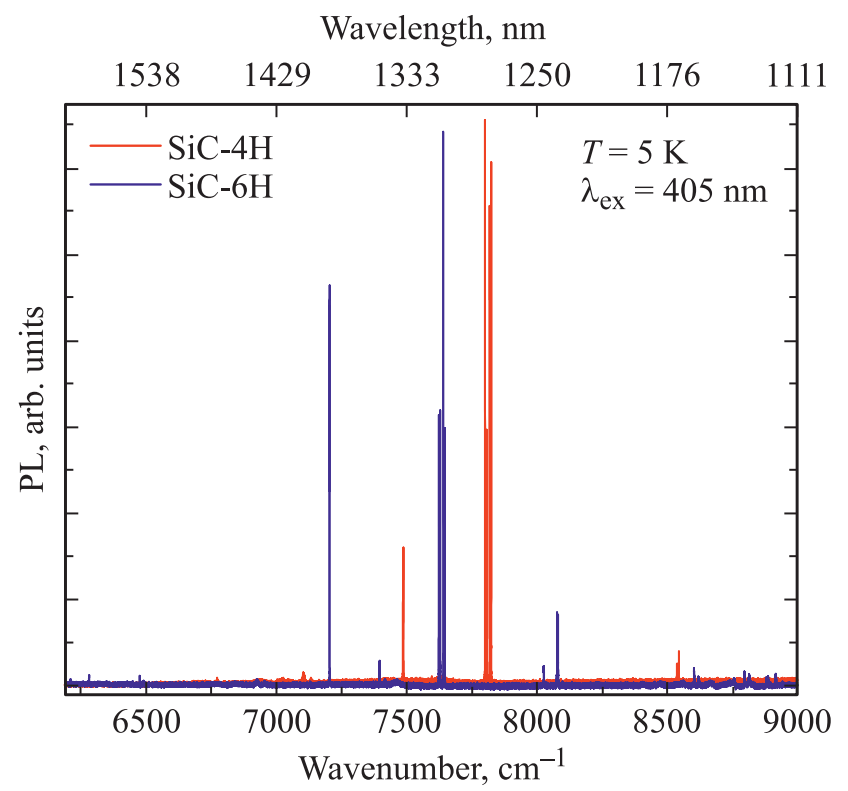

Рис. 3. Обзорный спектр люминесценции в ближнем ИК диапазоне гексагональных модификаций $\mathrm{SiC}(4 \mathrm{H}-$ красный спектр, $6 \mathrm{H}$ - синий) при температуре $5 \mathrm{~K}$.

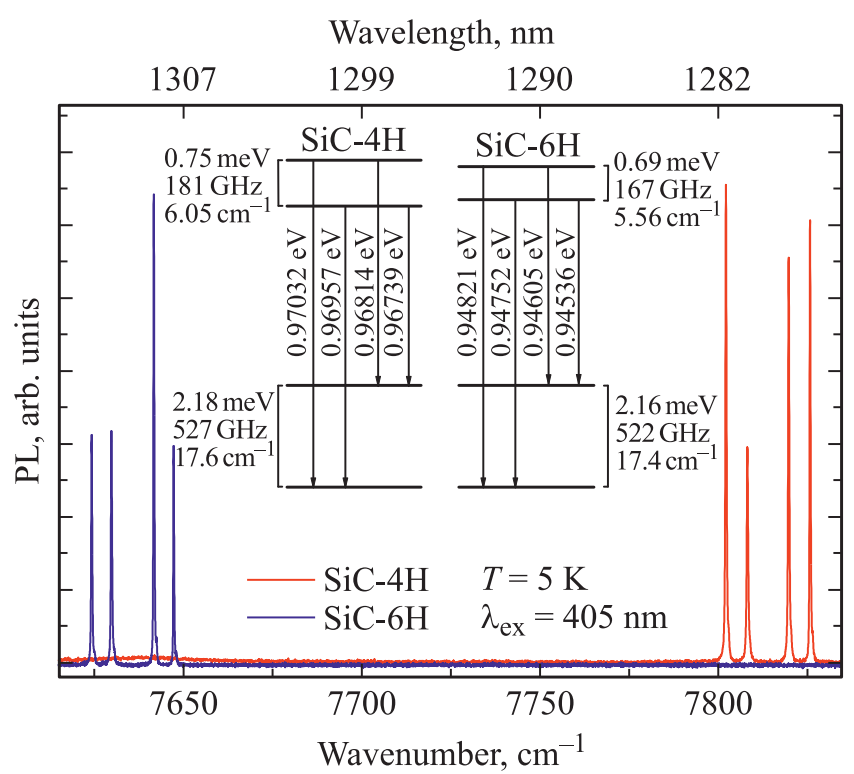

Рис. 4. Спектр люминесценции $\mathrm{SiC}$ в области $1.3 \mu \mathrm{m}$ при температуре $5 \mathrm{~K}$. Красный спектр принадлежит модификации $4 \mathrm{H}$, синий $-6 \mathrm{H}$. На вставке представлены схемы энергетических уровней для наблюдаемых линий, величины расщепления основного и возбужденного уровней, энергии переходов (слева для $\mathrm{SiC}-4 \mathrm{H}$, справа для $\mathrm{SiC}-6 \mathrm{H})$. 
Положение линий в низкотемпературных спектрах ИК люминесценции для модификации SiC-4Н (левая часть) и для модификации $\mathrm{SiC}-6 \mathrm{H}$ (правая часть)

\begin{tabular}{|c|c|c|c|c|c|c|c|}
\hline \multicolumn{4}{|c|}{$\mathrm{SiC}-4 \mathrm{H}$} & \multicolumn{4}{|c|}{$\mathrm{SiC}-6 \mathrm{H}$} \\
\hline $\mathrm{cm}^{-1}$ & $\mathrm{~nm}$ & $\mathrm{eV}$ & Описание & $\mathrm{cm}^{-1}$ & $\mathrm{~nm}$ & $\mathrm{eV}$ & Описание \\
\hline $\begin{array}{l}7825.6 \\
7819.6 \\
7808.1 \\
7802.1\end{array}$ & $\begin{array}{l}1277.86 \\
1278.84 \\
1280.72 \\
1281.71\end{array}$ & $\begin{array}{l}0.97025 \\
0.96951 \\
0.96808 \\
0.96734\end{array}$ & $\begin{array}{l}\text { Очень интенсивная } \\
\text { и узкая } \\
D=23.5 \mathrm{~cm}^{-1}\end{array}$ & $\begin{array}{l}7647.4 \\
7641.9 \\
7630.0 \\
7624.4\end{array}$ & $\begin{array}{l}1307.63 \\
1308.58 \\
1310.62 \\
1311.58\end{array}$ & $\begin{array}{l}0.94816 \\
0.94747 \\
0.94600 \\
0.94531\end{array}$ & $\begin{array}{l}\text { Очень интенсивная } \\
\text { и узкая } \\
D=23.5 \mathrm{~cm}^{-1}\end{array}$ \\
\hline 7638 & 1309.24 & 0.94699 & Слабая & 7462 & 1340.12 & 0.92517 & Слабая \\
\hline $\begin{array}{l}7488.68 \\
7487.24\end{array}$ & $\begin{array}{l}1335.349 \\
1335.606\end{array}$ & $\begin{array}{l}0.92848 \\
0.92830\end{array}$ & $\begin{array}{l}\text { Дублет } \\
D=1.5 \mathrm{~cm}^{-1}\end{array}$ & $\begin{array}{l}7397.4 \\
7396.5\end{array}$ & $\begin{array}{l}1351.83 \\
1351.99\end{array}$ & $\begin{array}{l}0.91716 \\
0.91705\end{array}$ & $\begin{array}{l}\text { Дублет } \\
D=0.9 \mathrm{~cm}^{-1}\end{array}$ \\
\hline $\begin{array}{l}7133.9 \\
7109.40 \\
7104.72\end{array}$ & $\begin{array}{l}1401.76 \\
1406.588 \\
1407.515\end{array}$ & $\begin{array}{l}0.88449 \\
0.88145 \\
0.88087\end{array}$ & $\begin{array}{l}\text { Дублет }(+3-я \text { линия }) \\
D=29.2 \mathrm{~cm}^{-1} \\
d=4.7 \mathrm{~cm}^{-1}\end{array}$ & $\begin{array}{l}6956.5 \\
6931.5 \\
6927\end{array}$ & $\begin{array}{l}1437.50 \\
1442.69 \\
1443.63\end{array}$ & $\begin{array}{l}0.86250 \\
0.85940 \\
0.85884\end{array}$ & $\begin{array}{l}\text { Дублет }(+3-я \text { линия }) \\
D=29.5 \mathrm{~cm}^{-1} \\
d=4.5 \mathrm{~cm}^{-1}\end{array}$ \\
\hline 6940 & 1440.92 & 0.8605 & Слабая, широкая & 6760 & 1479.29 & 0.83813 & Слабая, широкая \\
\hline
\end{tabular}

Примечание. Группы одинаковых линий, смещенных относительно друг друга для различных модификаций, разделены двойными линиями. $D$ полное расщепление группы линий

зительно одинаковом расстоянии $\left(176-180 \mathrm{~cm}^{-1}\right)$ от своих „аналогов““ в спектре политипа 6Н. Причем видна тенденция, что спектры в модификации 4Н смещены в высокоэнергетичную область (синее смещение). Это, вероятно, говорит об одинаковой природе таких центров окраски, находящихся, однако, в различных политипных структурах. Из того, что исследуемые образцы являлись номинально чистыми, не содержали примесей других элементов, можно сделать вывод, что наблюдаемые линии люминесценции и поглощения связаны с собственными дефектами кристаллической решетки карбида кремния, такими как вакансии углерода и кремния (Si-VC, SiC-V и др.), собственный межузельный атом, примесные атомы замещения (CSi-C, $\mathrm{SiC}-\mathrm{Si})$, а также их комбинации.

\section{Заключение}

Впервые были зарегистрированы чрезвычайно узкие линии в спектрах ИК люминесценции в области 1.5-1.2 $\mu$ m гексагональной модификации $\mathrm{SiC}(4 \mathrm{H}, 6 \mathrm{H})$ и проведена их частичная идентификация. Обнаружены особенности спектра, не упомянутые в предшествующих работах и подлежащие дальнейшему экспериментальному и теоретическому исследованию, а именно смещение линий люминесценции в зависимости от политипной модификации кристалла. Полученные результаты дают основу для более детальных исследований, в частности для определения конкретных дефектов, обусловливающих те или иные линии, а также для поиска их возможных практических применений в различных областях, таких как квантовая сенсорика, оптическая квантовая память, источники одиночных фотонов.

\section{Финансирование}

Работа выполнена на Уникальной научной установке (УНУ) ИСАН „Мультифункциональная широкодиапазонная спектроскопия высокого разрешения“ (УНУ МШСВР ИСАН) при финансовой поддержке гранта РНФ № 19-72-10132.

\section{Конфликт интересов}

Авторы заявляют, что у них нет конфликта интересов.

\section{Список литературы}

[1] Fisher G.R., Barnes P. // Phil. Mag. B. 1990. V. 61. P. 217-236. doi 10.1080/13642819008205522

[2] Gruber A., Dräbenstedt A., Tietz C., Fleury L., Wrachtrup J., von Borczyskowski C. // Science. 1997. V. 276. P. 2012-2014. doi $10.1126 /$ science. 276.5321 .2012

[3] Beveratos A., Kühn S., Brouri R., Gacoin T., Poizat J.-P., Grangier P. // Eur. Phys. J. D. 2002. V. 18. P. 191-196. doi 10.1140/epjd/e20020023

[4] Taylor J., Cappellaro P., Childress L., Jiang L., Budker D., Hemmer P.R., Yacoby A., Walsworth R., Lukin M.D. // Nat. Phys. 2008. V. 4. P. 810-816. doi 10.1038/nphys 1075

[5] Neumann P., Jakobi I., Dolde F., Burk C., Reuter R., Waldherr G., Honert J., Wolf T., Brunner A., Shim J.H., Suter D., Sumiya H., Isoya J., Wrachtrup J. // Nano Lett. 2013. V. 13. P. 2738-2742. doi 10.1021/n1401216y

[6] Anisimov A.N., Soltamov V.A., Breev I.D., Khalisov M.M., Babunts R.A., Ankudinov A.V., Baranov P.G. // Jetp Lett. 2018. V. 108. P. 610-615. doi 10.1134/S0021364018210063

[7] Veinger A.I., Ilïn V.A., Tairov Yu.M., Tsvetkov V.F. // Soviet Physics: Semicond. 1979. V. 13. P. 1385.

[8] Vainer V.S., Ilin V.A. // Soviet Physics: Solid State. 1981. V. 23. P. 2126. 
[9] Kraus H., Soltamov V., Riedel D., Väth S., Fuchs F., Sperlich A., Baranov P.G., Dyakonov V., Astakhov G.V. // Nat. Phys. 2014. V. 10. P. 157-162. doi 10.1038/nphys2826

[10] Koehl W.F., Buckley B.B., Heremans F.J., Calusine G., Awschalom D.D. // Nature. 2011. V. 479. P. 84-87. doi: $10.1038 /$ nature 10562

[11] Soltamov V.A., Soltamova A.A., Baranov P.G., Proskuryakov I.I. // Phys. Rev. Lett. 2012. V. 108. P. 226402. doi 10.1103/PhysRevLett.108.226402

[12] Soltamov V.A., Kasper C., Poshakinskiy A.V., Anisimov A.N., Mokhov E.N., Sperlich A., Tarasenko S.A., Baranov P.G., Astakhov G.V., Dyakonov V. // Nat. Commun. 2019. V. 10. P. 1678. doi 10.1038/s41467-019-09429-x

[13] Kraus H., Soltamov V., Fuchs F., Simin D., Sperlich A., Baranov P.G., Astakhov G.V., Dyakonov V. // Sci. Rep. 2015. V. 4. P. 5303. doi $10.1038 /$ srep05303

[14] Simin D., Soltamov V.A., Poshakinskiy A.V., Anisimov A.N., Babunts R.A., Tolmachev D.O., Mokhov E.N., Trupke M., Tarasenko S.A., Sperlich A., Baranov P.G., Dyakonov V., Astakhov G.V. // Phys. Rev. X. 2016. V. 6. P. 031014. doi 10.1103/PhysRevX.6.031014

[15] Soltamov V.A., Tolmachev D.O., Il'in I.V., Astakhov G.V., Dyakonov V.V., Soltamova A.A., Baranov P.G. // Physics of the Solid State. 2015. V. 57. P. 891-899. doi 10.1134/S1063783415050285

[16] Anisimov A.N., Simin D., Soltamov V.A., Lebedev S.P., Baranov P.G., Astakhov G.V., Dyakonov V. // Sci. Rep. 2016. V. 6. P. 33301. doi 10.1038/srep33301

[17] Castelletto S., Johnson B.C., Ivády V., Stavrias N., Umeda T., Gali A., Ohshima T. // Nat. Mater. 2014. V. 13. P. 151-6. doi $10.1038 /$ nmat3806

[18] Baranov P.G., Bundakova A.P., Soltamova A.A., Orlinskii S.B., Borovykh I.V., Zondervan R., Verberk R., Schmidt J. // Phys. Rev. B. 2011. V. 83. P. 125203. doi 10.1103/PhysRevB.83.125203

[19] Lohrmann A., Johnson B.C., McCallum J.C., Castelletto S. // Rep. Prog. Phys. 2017. V. 80. P. 034502. doi 10.1088/13616633/aa5171

[20] Christle D.J., Falk A.L., Andrich P., Klimov P.V., Hassan J.U., Son N.T., Janzén E., Ohshima T., Awschalom D.D. // Nat. Mater. 2015. V. 14. P. 160-163. doi 10.1038/nmat4144

[21] Feldman D.W., Parker J.H., Choike W.J., Patrick L. // Phys. Rev. 1968. V. 173. P. 787. doi 10.1103/PhysRev.173.787

[22] Nakashima S., Harima H. // Phys. Stat. Sol. A. 1997. V. 162. P. 39. doi 10.1002/1521-396X(199707)162:1<39::AIDPSSA39>3.0.CO;2-L

[23] Chikvaidze G., Mironova-Ulmane N., Plaude A., Sergeev O. // Latv. J. Phys. Tech. Sci. 2004. V. 51. P. 51-57. doi 10.2478/lpts2014-0019

[24] Sörman E., Son N.T., Chen W.M., Kordina O., Hallin C., Janzén E. // Phys. Rev. B. 2000. V. 61. P. 2613. doi 10.1103/PhysRevB.61.2613

[25] Zargaleh S.A., Eble B., Hameau S., Cantin J.-L., Legrand L., Bernard M., Margaillan F., Lauret J.-S., Roch J.-F., von Bardeleben H.J., Rauls E., Gerstmann U., Treussart F. // Phys. Rev. B. 2016. V. 94. P. 060102(R). doi 10.1103/PhysRevB.94.060102 